\title{
Tailored polyurethane acrylate blend for large-scale and high-performance micropatterned dry adhesives
}

\author{
Dan $\mathrm{Yu}^{1}{ }^{1}$, René Hensel ${ }^{1}$, Dirk Beckelmann ${ }^{1}$, Michael Opsölder ${ }^{1}$, Bruno Schäfer ${ }^{1}$, \\ Karsten Moh ${ }^{1}$, Peter William de Oliveira ${ }^{1}$, and Eduard Arzt ${ }^{1,2, \star}$ \\ ${ }^{1}$ INM-Leibniz Institute for New Materials, Campus D2 2, 66123 Saarbrücken, Germany \\ ${ }^{2}$ Department of Materials Science and Engineering, Saarland University, 66123 Saarbrücken, Germany
}

Received: 6 March 2019

Accepted: 1 June 2019

Published online:

21 June 2019

(C) The Author(s) 2019

\begin{abstract}
Continuous roll-to-roll fabrication is essential for transferring the idea of bioinspired, fibrillar dry adhesives into large-scale, synthetic, high-performance adhesive tapes. Toward this aim, we investigated process parameters that allow us to control the morphology and the resulting adhesion of mushroom-shaped micropatterned surfaces. Flexible silicone templates enabled the replication process of the polyurethane acrylate pre-polymer involving UV-light-induced cross-linking. For this paper, we particularly tailored the polyurethane acrylate pre-polymer by adding chemical components to tune UV curing kinetics and to reduce oxygen inhibition of radicals. We found that higher intensities of the UV light and faster reaction kinetics improved the quality of the microstructures, i.e., a larger cap diameter of the mushroom tips was achieved. The polymer blend U6E4 exhibited the fastest curing kinetics, which resulted in a micromorphology similar to that of the Ni-shim master structures. Best adhesion results were obtained for adhesive tapes made from U6E4 with $116 \mathrm{kPa}$ pull-off stress, $1.4 \mathrm{~N} \mathrm{~cm}^{-1}$ peel strength and $71 \mathrm{kPa}$ shear strength. In addition, repeated attachment-detachment tests over 100,000 cycles demonstrated strong robustness and reusability.
\end{abstract}

\section{Introduction}

Geckoes and some species of insects and spiders show superior dry adhesion due to their hairy attachment pads which enable them to locomote on various surfaces [1-5]. Mimicking those by transferring the underlying "contact splitting" principle into synthetic adhesives exhibits large potential for next generation adhesives [3, 6, 7]. Several studies have reported that splitting a nominal flat adhesive surface into several discrete contacts improved their adhesion performance; the reasons are related to scaling effects, enhanced compliance of the contact and a higher defect tolerance in combination with crack trapping mechanisms, which dissipate stored strain energy and prevent uncontrolled detachment [7-16]. Further work has focused on the optimization of design parameters such as tip geometry, aspect ratio

Address correspondence to E-mail: eduard.arzt@leibniz-inm.de 
of the microstructures, areal density $[11,17,18]$ and mechanical properties such as (visco)elasticity and stiffness gradients [19-23]. In addition, counter surface roughness [24], substrate elasticity [9], temperature [25] and humidity [26] further impact the performance and have to be taken into account in real-world applications.

Despite great progress in understanding the underlying concepts and the successful fabrication on a laboratory scale [17, 27-29], the transfer to largescale or even continuous manufacturing remains challenging due to restrictions in materials selection and due to the complex shape of the required microstructures [7]. Most critically, a continuous fabrication process requires materials with short curing times. Thus, light-induced cross-linking reactions are preferred, compared to thermally induced reactions, which often require longer heating times. Acrylate- or methacrylate-based polymers are materials with tunable viscoelasticity and toughness suitable for generation of micropatterned functional surfaces [30-37]. By adding photo-cleavable entities (i.e., photoinitiators), radical-based cross-linking reactions can be induced by exposure to light. In addition, their properties can be tailored by tuning the chemical composition of the pre-polymers, which allows customizing for specific demands. In general, (meth)acrylate-based polymer blends contain an oligomer with (meth)acryloxy group, a photoinitiator and several modulators, which control properties such as viscosity of the pre-polymer [30-32], surface free energy [30, 33, 38, 39], permeability [39] and curing kinetics. Mechanical properties can be tuned by the amount of functional entities (i.e., (meth)acryloxy group), the molecular weight of the oligomer and the chemical structure of the modulators, i.e., cycloaliphatic or linear chains [30, 32-34, 40]. Customized (meth)acrylate-based materials have been reported as mold materials for replica molding as well as materials for generating micropatterned surfaces by a wide range of lithographic techniques [28, 33, 41, 42]. For example, Lee et al. reported on mushroom-shaped dry adhesives made from polyurethane acrylate (PUA) in a continuous roll-to-roll process. They took advantage of incomplete curing during fabrication of micropillars and added the mushroom tips by a subsequent compression and final curing treatment [43]. Another study by Yi et al. [34] demonstrated a roll-to-roll process for polyurethane acrylate materials, but it was limited to transparent templates.

We recently reported a one-step process for continuous fabrication of high-performance mushroomshaped dry adhesives on large-scale roll-to-roll system, featuring a total web length of $24 \mathrm{~m}$ and a steel imprinting roll of $50 \mathrm{~cm}$ in diameter, to simulate an industrial fabrication process [44]. We found that the complex geometry including undercuts of mushroom-shaped adhesives can be replicated into polyurethane-acrylate (PUA)-based materials by using flexible, non-transparent templates and controlled compressive loads during the imprint process. In adhesion tests, we identified the backing layer thickness as a parameter relevant for the adhesion performance. Briefly, for too thin backing layers, the adhesion strength of the microstructures and their interfacial bonding to the polyethylene terephthalate (PET) carrier film decreased or was lost.

In the present work, we will show that the processing window can be expanded by introducing a double-layer coating strategy. Furthermore, we will provide detailed process parameters for precise replication of mushroom tips and will correlate morphology with adhesion results. Issues of replicating microstructures by using UV-curable materials will be discussed from aspects of material compositions: We varied the chemical composition of the PUA-based microstructures by blending with additives to optimize the processability in a continuous fabrication and the resulting adhesion properties. Additives to control UV-curing kinetics, the formation of mushroom caps and the influence of the mechanical properties of the materials were investigated. As a result, a formulation for improved adhesive mushroom-shaped microstructures, with dimensions replicating accurately those of the $\mathrm{Ni}$ shim master structures, and for achieving optimal adhesion characteristics will be presented.

\section{Experimental section}

\section{Material preparation}

For the micropatterned dry adhesives, pre-polymer blends based on aliphatic urethane diacrylate oligomers, UA16 (Miramer UA5216, Miwon Specialty Chemical Co. Ltd., Gwanggyo, South Korea) were used. The photoinitiator Omnirad 500 (IGM Resins 
Table 1 Compositions and materials properties of the adhesives and the flexible templates

\begin{tabular}{|c|c|c|c|c|c|}
\hline Material & Description $^{\mathrm{a}}$ & $\begin{array}{l}\text { Viscosity at } \\
25^{\circ} \mathrm{C}(\mathrm{Pa} \mathrm{s})\end{array}$ & $\begin{array}{l}\text { Elastic modulus } \\
(\mathrm{MPa})^{\mathrm{b}}\end{array}$ & $\begin{array}{l}\text { Elongation at } \\
\text { break }(\%)^{\mathrm{c}}\end{array}$ & $\begin{array}{l}\text { Surface free } \\
\text { energy }\left(\mathrm{mJ} \mathrm{m}^{-2}\right)\end{array}$ \\
\hline UA16 & Miramer UA5216 & 13.7 & 359 & 326 & 40.3 \\
\hline U6L7 & UA16 + 10\% Laromer 8887 & 8.2 & 243 & 204 & 29.2 \\
\hline U6S9 & UA16 + 1\% Miramer SIP900 & 13.9 & 357 & 196 & 24.6 \\
\hline U6E4 & UA $16+20 \%$ Miramer ES4420 & 10.6 & 150 & 448 & 24.3 \\
\hline nPDMS & Non-transparent PDMS & - & 0.76 & 700 & 25.8 \\
\hline tPDMS & Transparent PDMS & - & 1.64 & 400 & 24.6 \\
\hline
\end{tabular}

${ }^{a}$ All the UA16 blends (UA16, U6L7, U6S9, U6E4) included 5 wt \% Omnirad 500 (photoinitiator)

${ }^{\mathrm{b}}$ Represents storage modulus at room temperature obtained by DMTA.

${ }^{\mathrm{c}}$ Measured by tensile test

B.V., Waalwijk, The Netherlands) was added to all UA16-based blends in a concentration of $5 \mathrm{wt} \%$. For different formulations, modulators were added: U6L7 contained $10 \mathrm{wt} \%$ Laromer LR 8887 (BASF AG, Ludwigshafen, Germany); U6S9 contained $1 \mathrm{wt} \%$ Miramer SIP900 (Miwon Co.); U6E4 contained 20 wt\% Miramer ES4420 (Miwon Co.). All compositions for each pre-polymer blend are summarized in Table 1. All blends were mixed at $2350 \mathrm{rpm}$ and degassed at $1 \mathrm{mbar}$ for $3 \mathrm{~min}$ using a SpeedMixer (DAC600.2 VAC-P, Hauschild \& Co. KG, Hamm, Germany).

For the flexible templates, two types of silicones were used: Elastosil M4601 (nPDMS, Wacker Chemie AG, München, Germany) and Elastosil M4644 (tPDMS, Wacker AG). The two-component polydimethylsiloxanes were mixed at $2350 \mathrm{rpm}$ and degassed at $1 \mathrm{mbar}$ for $3 \mathrm{~min}$ using a SpeedMixer. The pre-polymers were cast into a circular mold (diameter $130 \mathrm{~mm}$; depth $5 \mathrm{~mm}$ ), in which the master structure was mounted. A micropatterned Ni-shim (Temicon GmbH, Dortmund, Germany) was used as a master structure that comprised mushroom-shape micropillars with diameters and heights of $50 \mu \mathrm{m}$. The diameters of the mushroom tips were in the range of $66-76 \mu \mathrm{m}$. The pillar array was hexagonally arranged with a center-to-center distance of $100 \mu \mathrm{m}$. The mushroom tips hence cover an area fraction of about $42.9 \%$. The PDMS pre-polymer was then cured at $70{ }^{\circ} \mathrm{C}$ for $1 \mathrm{~h}$, and the negative microstructure was received after gentle demolding. Several PDMS stamps were prepared by repeating this procedure and then trimmed into square shape, and eventually glued onto the imprinting roll.

\section{Materials characterization}

Viscosities of the pre-polymer blends were measured with a rheometer (Physica MCR300, Anton Paar $\mathrm{GmbH}$, Graz, Austria) in the temperature range between 25 and $80{ }^{\circ} \mathrm{C}$ at a constant shear rate of $1 \mathrm{~s}^{-1}$. For all materials, dynamic mechanic thermal analyses (DMTA) were performed in the temperature range from -100 to $120{ }^{\circ} \mathrm{C}$ in tensile mode at an oscillatory frequency of $1 \mathrm{~Hz}$ under $\mathrm{N}_{2}$ atmosphere. The sample dimensions were $30 \mathrm{~mm} \times 5.5 \mathrm{~mm} \times 2 \mathrm{~mm}$. Elongations at break were measured by (quasi-static) tensile tests (Material Testing Machine Xforce $\mathrm{P}$, Zwick \& Roell GmbH \& Co. KG, Ulm, Germany) with a crosshead moving rate of $20 \mathrm{~mm} \mathrm{~min}^{-1}$. Dogbone-shaped specimens with a thickness of $3 \mathrm{~mm}$ exhibited a gage length of 60 and a width of $8 \mathrm{~mm}$. The width of the grips was $17 \mathrm{~mm}$. For all mechanical tests, UA16 blends were cured by UV exposure (365 nm) for $5 \mathrm{~min}$; the silicones were thermally cured at $70{ }^{\circ} \mathrm{C}$ for $1 \mathrm{~h}$.

Surface free energies were examined by contact angle goniometry (OCA 35, analysis software: SCA20; DataPhysics Instruments $\mathrm{GmbH}$, Filderstadt, Germany) using water and hexadecane as testing liquids. Smooth films with $120 \mu \mathrm{m}$ thickness for static contact angle measurements were prepared by coating UA16 polymer blends or PDMS pre-polymers onto flat PET substrates, following by 5 -min UV exposure for UA16 polymer blends and thermal curing at $70{ }^{\circ} \mathrm{C}$ for PDMS. The surface free energy was deducted from the obtained contact angles by using $\mathrm{Wu}^{\prime}$ s harmonic method $[45,46]$.

UV-curing rates of the polymer blends were measured by UV-DSC (Mettler Toledo $\mathrm{GmbH}$, Gießen, 


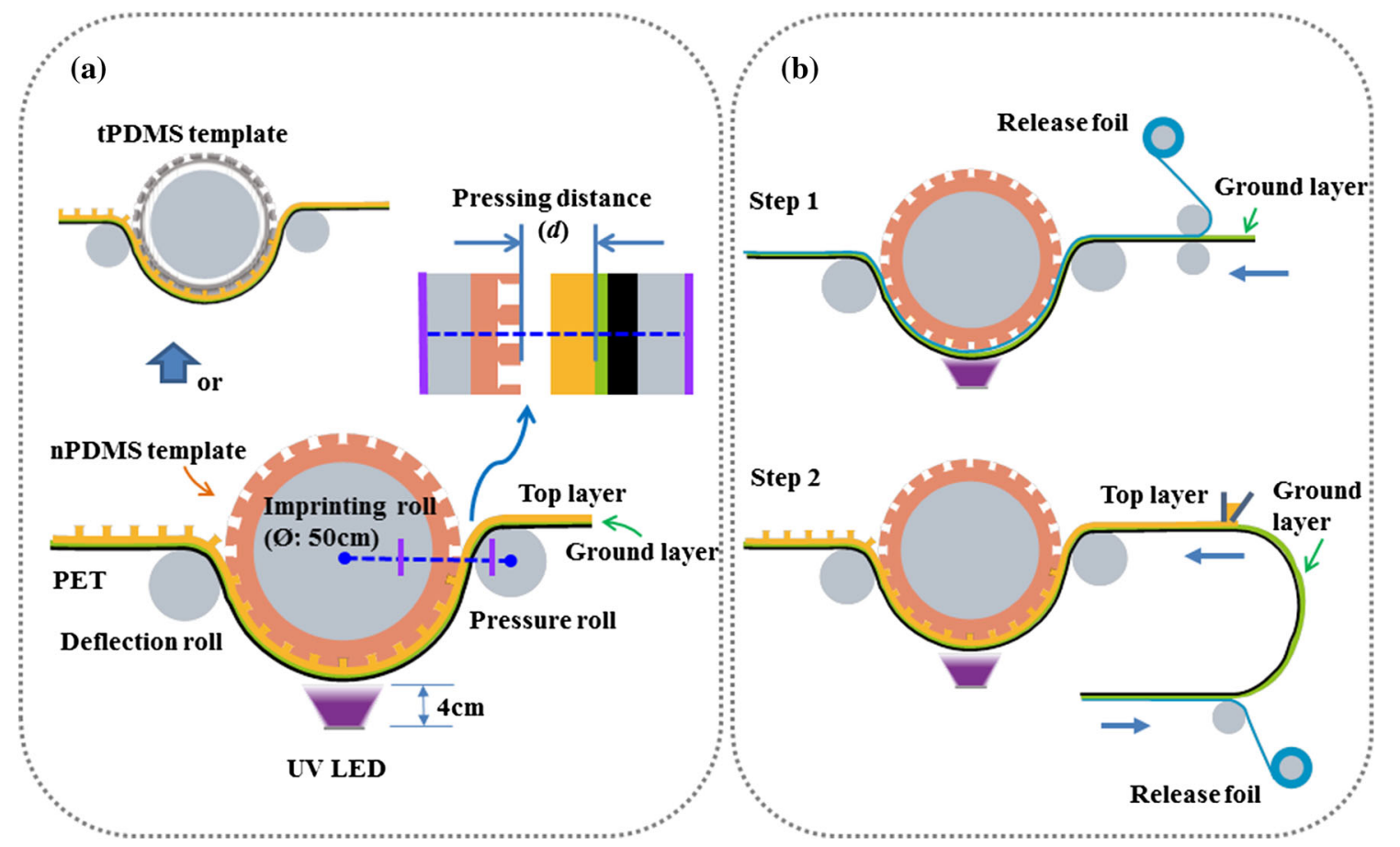

Figure 1 Schematics of the roll-to-roll setup used: a Illustration of the imprint unit: The flexible template (nPDMS or tPDMS) was glued onto the imprinting roll. The top layer was coated onto the

Germany) under $\mathrm{N}_{2}$ atmosphere. For each blend, 8-10 mg was tested in an aluminum pan without a lid at $25^{\circ} \mathrm{C}$. The heat flow was recorded over a time frame of 6 min (2 min before UV exposure, 3-min UV exposure, $1 \mathrm{~min}$ after exposure).

For scanning electron microscopy (SEM), the samples were sputter-coated with a conductive gold layer at $30 \mathrm{~mA}$ for $40 \mathrm{~s}$ using a Jeol JFC-1300 auto fine coater (Jeol Ltd., Akishima, Japan). Secondary electron images were acquired at $5 \mathrm{kV}$ accelerating voltage in high vacuum conditions using an FEI Quanta 400 FEG (Thermo Fisher Scientific, Waltham, USA).

\section{Roll-to-roll processing}

For continuous fabrication, a roll-to-roll system (Jakob Weiß \& Söhne GmbH, Sinsheim, Germany) with a total web length of $24 \mathrm{~m}$ was used. The system consists of several units including coating, thermal drying, imprinting and UV curing and delamination. The imprinting unit is the core of the machine, which includes an imprinting roll and two backing rolls placed on each side; a pressure roll pressed the prepolymer (i.e., wet coating) against the imprinting roll, and a deflection roll guided the delamination ground layer and then pressed into the micropatterned template. b Illustration of roll-to-roll fabrication of micropatterned adhesive film via a double-layer process.

(Fig. 1a). The flexible transparent (tPDMS) or nontransparent (nPDMS) silicone templates were wrapped onto the imprinting roll. The UV-LED radiator with a maximum power of $6 \mathrm{~W} \mathrm{~cm} \mathrm{~cm}^{-2}$ at $365 \mathrm{~nm}$ was placed under the imprinting roll. $30 \%$ or $50 \%$ of UV power was used for different trials for comparison purposes. Detailed processing parameters for each experiment are summarized in Table 2.

In the present work, the roll-to-roll manufacturing followed a two-step process as illustrated in Fig. 1b: First a non-patterned film (UA16 or U6L7) with a $30 \mu \mathrm{m}$ wet coating thickness was formed onto the PET substrate (75 $\mu \mathrm{m}$ thickness, Melinex 506, DuPont Teijin Films Europe, Luxemburg) by covering the wet film with a release foil (polyethylene film, $23 \mu \mathrm{m}$ Hostaphan MP 23, Mitsubishi Polyester Film GmbH, Wiesbaden, Germany) to protect the wet film against direct contact with the micro-patterning molds. After UV curing of this non-patterned ground layer, the release foil was removed. In a second step, the microstructures were imprinted based on coatings of UA16, U6S9 or U6E4 (90 or $120 \mu \mathrm{m}$ wet coating thickness) as top coating on the ground layer. During imprinting, the distance between the ground layer and the flexible template, $d$, was adjusted by moving 
Table 2 The parameters of roll-to-roll process

\begin{tabular}{|c|c|c|c|c|c|c|}
\hline \multirow[t]{3}{*}{ Samples } & \multirow{3}{*}{$\begin{array}{l}\text { Ground } \\
\text { layer } \\
\text { Material }\end{array}$} & \multicolumn{5}{|c|}{ Process parameters } \\
\hline & & \multicolumn{5}{|c|}{ Top layer } \\
\hline & & Material & $\begin{array}{l}\text { UV power } \\
(\%)\end{array}$ & $\begin{array}{l}\text { Thickness } \\
(\mu \mathrm{m})\end{array}$ & Distance $^{\mathrm{a}}(\mu \mathrm{m})$ & Mold material \\
\hline 90_(-245 $\mu \mathrm{m})$ & UA16 & UA16 & $30 / 50$ & 90 & -245 & nPDMS \\
\hline $\begin{array}{l}120 \_(-245 \mu \mathrm{m}), \\
120 \_(-303 \mu \mathrm{m})\end{array}$ & UA16 & UA16 & 50 & 120 & $-245,-303$ & $\begin{array}{l}\text { tPDMS, } \\
\text { nPDMS }\end{array}$ \\
\hline U6S9 & U6L7 & U6S9 & 50 & 120 & $-245,-303,-362$ & nPDMS \\
\hline U6E4 & U6L7 & U6E4 & 50 & 120 & $-245,-303,-362$ & nPDMS \\
\hline
\end{tabular}

${ }^{a}$ Represents distance between the flexible template and the ground layer. Positive value means that there is a gap between the flexible mold and ground layer; negative value means that the flexible mold is compressed

the pressure roll to control the filling of the microcavities by the pre-polymer. Positive values of $d$ mean that there was a gap between the ground layer (without considering the top layer) and the flexible template, whereas negative values represent the flexible template being compressed. Upon UV curing, the microstructures were demolded from the flexible template.

\section{Adhesion measurements}

Adhesion tests were carried out on a custom-built testing device as illustrated in Fig. 2a. The device is composed of an interferometer, a pivotable stage and a smooth glass sphere with curvature radius of $15 \mathrm{~mm}$ mounted on a glass beam with a spring constant of $2241 \mathrm{~N} \mathrm{~m}^{-1}$. Forces were calculated based on the beam deflection and the spring constant [24]. Samples with a size of $15 \mathrm{~mm} \times 15 \mathrm{~mm}$ were cut (a)

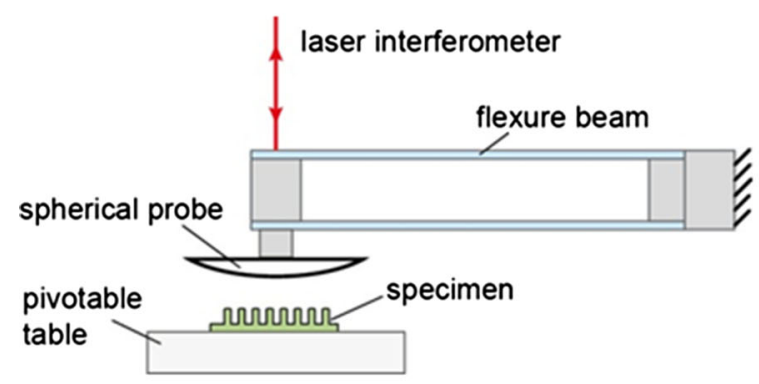

from the micropatterned films and subsequently glued to a glass slide with a UV adhesive (BO MV76002, Bohle AG, Haan, Germany). A typical force-displacement curve for a normal pull-off experiment using a spherical probe is shown in Fig. $2 b$. The glass sphere was brought in contact with the samples at a velocity of $5 \mu \mathrm{m} \mathrm{s}^{-1}$ until a compressive preload of $30 \mathrm{mN}$ was reached. The apparent contact area, A, was estimated from the radius of the glass sphere and the indentation depth (which is the difference between the displacement at preload and that achieved at first contact) from the equation: $A=\pi\left[R^{2}-\left(R^{2}-\delta^{2}\right)\right]$, where $\mathrm{R}$ is the radius of the probe and $\delta$ is the indentation depth at preload. After preloading, the sphere was retracted in normal direction at a constant velocity of $5 \mu \mathrm{m} \mathrm{s}^{-1}$. The pulloff force was defined as the maximum tensile force before detachment. Pull-off stresses were determined

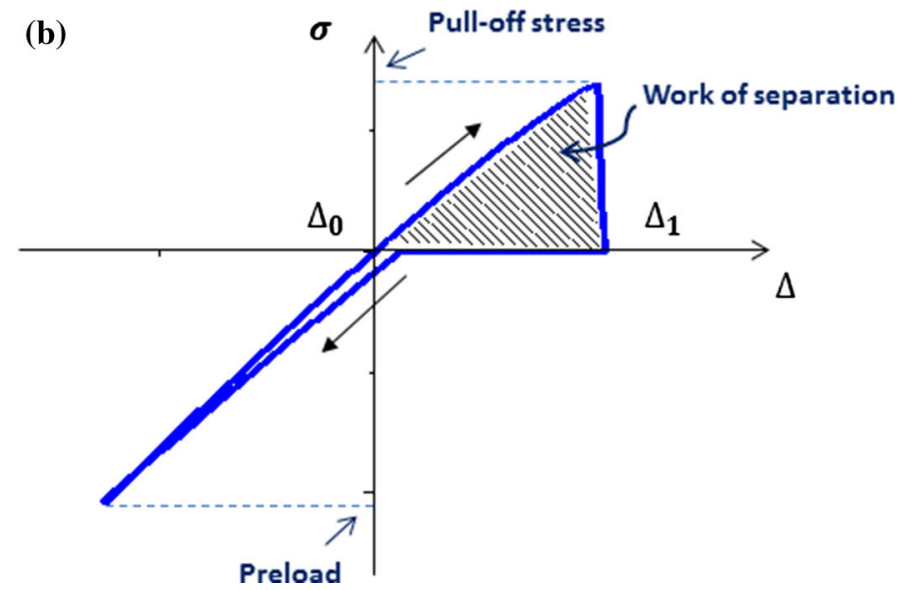

Figure 2 Principle of adhesion measurements: a Illustration of adhesion test device with a glass sphere (radius $15 \mathrm{~mm}$ ) as counter surface. $\mathbf{b}$ Stress-displacement curve from a normal adhesion test.
Maximum positive and negative stresses were defined as (tensile) pull-off stress and compressive preload, respectively. The enclosed area highlighted in the graph represents the work of separation. 
(a)

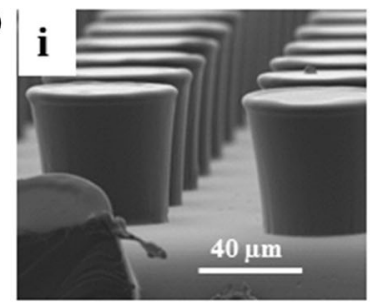

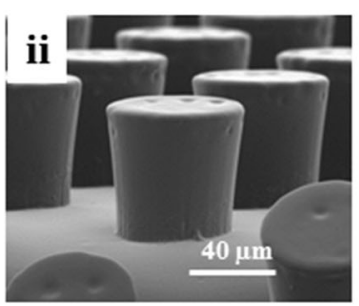

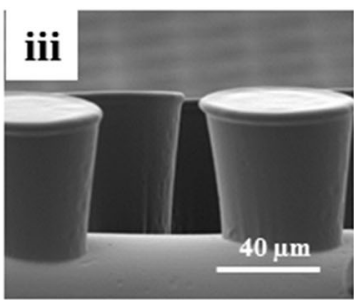

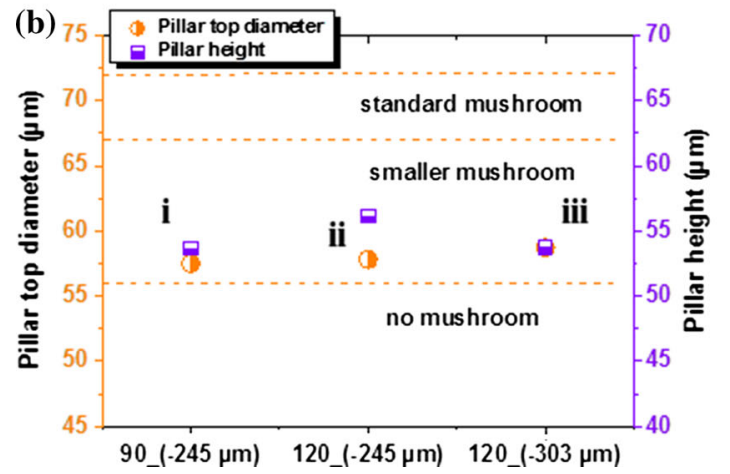

Figure 3 Influence of wet film coating thickness and mold compression on patterned microstructure and adhesion properties: a scanning electron micrographs of micropillars of UA16: (i) with $90-\mu$ m-thick top layer and obtained at $d=-245 \mu \mathrm{m}$; (ii) and (iii) with $120-\mu \mathrm{m}$-thick top layer,

by dividing pull-off forces by the apparent contact area, A, as described above. The work of separation was calculated by integrating the enclosed area of the stress-displacement curve in the tensile regime (see Fig. 2b). Six positions on each sample were measured, and the mean values were recorded.

Peel tests on smooth, flat glass substrates with a $90^{\circ}$ peel angle were performed with 24-mm-wide and 240-mm-long films. The peeling speed was $5 \mathrm{~mm} \mathrm{~s}^{-1}$. For comparison with our tapes, magic tape $\left(\mathrm{Scotch}^{\circledR}\right.$ Magic $^{\text {TM }}$ Tape, $3 \mathrm{M}$ Deutschland $\mathrm{GmbH}$, Neuss, Germany) was measured under the same condition. The normalized peel force was determined by dividing the measured forces by the width of the tapes.

Shear strength was examined by lap shear test in a tensile tester (Material Testing Machine Xforce $\mathrm{P}$, Zwick \& Roell GmbH \& Co. KG, Ulm, Germany). The adhesive strip was attached on a glass plate with a contact area of $20 \mathrm{~mm} \times 50 \mathrm{~mm}$. The crosshead speed was $5 \mathrm{~mm} \mathrm{~min}^{-1}$. Shear strength was calculated by dividing the maximum shear force by the contact area.

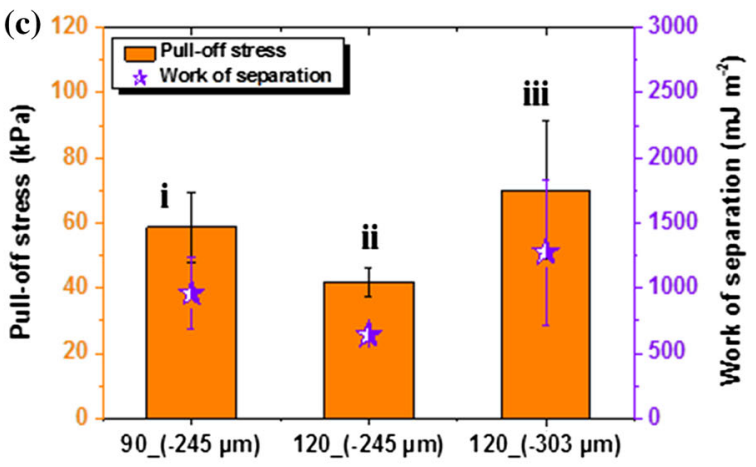

obtained at $d=-245 \mu \mathrm{m}$ and $-303 \mu \mathrm{m}$, respectively. All the samples were cured with UV light at $50 \%$ power. $\mathbf{b}$ Summary of pillar top diameter and pillar height and c pull-off stress and work of separation.

\section{Results and discussion}

\section{Process optimization}

The two-step replication, as shown in Fig. 1b, was successfully implemented into the continuous roll-toroll process: First, the plain ground layer (thickness $30 \mu \mathrm{m}$ ) was coated onto the PET carrier film. Second, the micropatterned adhesive layer was added. To study how the morphology as well as the adhesive properties of the composite film was affected by the thickness of the second layer, three different conditions were investigated: "90_(-245 $\mu \mathrm{m})$," "120_(- $245 \mu \mathrm{m})$ " and "120_(- $303 \mu \mathrm{m})$. " The first number in the notation represents the layer thickness of the second wet layer (in $\mu \mathrm{m}$ ), whereas the second number represents the set distance between the imprinting and the pressure roll during imprinting (see Fig. 1a). Negative distance implies compression between the template and the wet coating during the imprint. In this test, pure UA16 (without additives) was used for the ground and the second layer. The power of the UV curing lamp was set to $50 \%$. Scanning electron micrographs of the microstructures obtained from the three different imprint conditions are presented in Fig. 3a. Pillar dimensions such as 
(a)
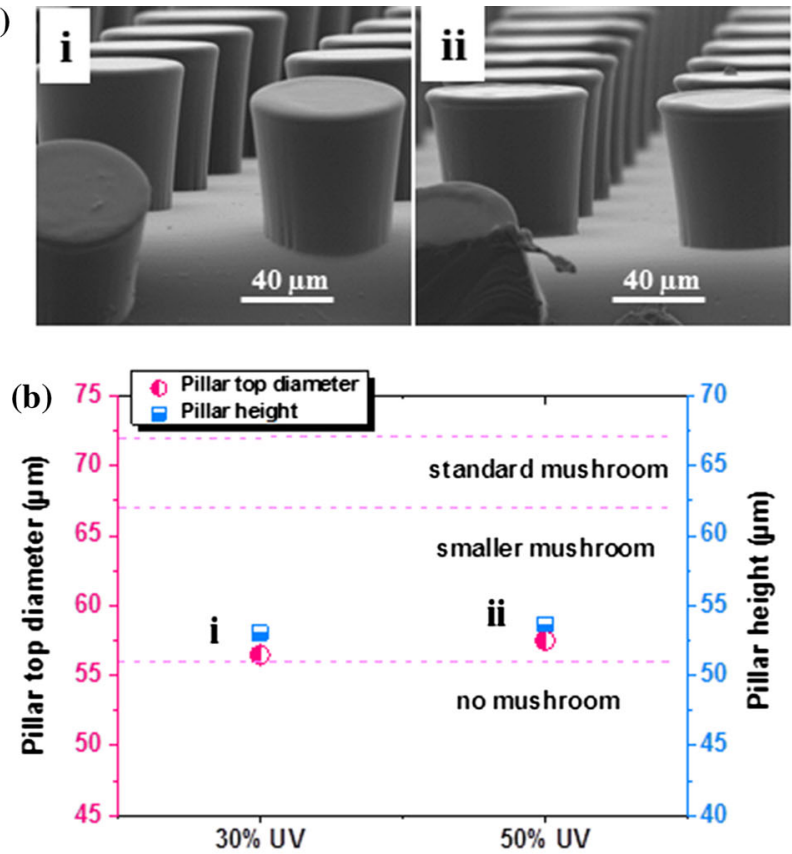

(c)

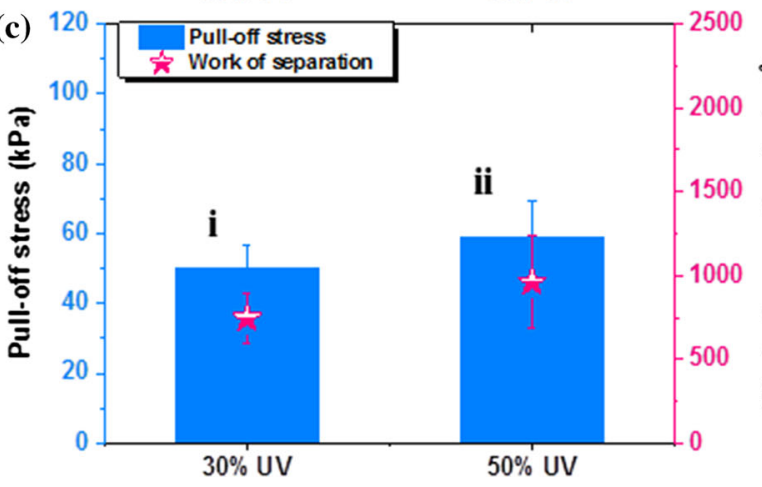

Figure 4 Influence of UV power and transparency of the PDMS template material on patterned microstructure and adhesion properties: a Scanning electron micrographs of micropillars of UA16, with $90-\mu \mathrm{m}$-thick top layer and obtained at $d=-245 \mu \mathrm{m}$, cured by UV light with power ratings of $30 \%$ (i) and $50 \%$ (ii); and with $120-\mu \mathrm{m}$-thick top layer, obtained at $d=-303 \mu \mathrm{m}$, fabricated with nPDMS (iii) and tPDMS (iv). UV power effect

pillar height and diameter of the pillar top are shown in Fig. 3b. The figure includes three regimes, highlighting the pillar top diameter: "standard mushroom" with diameters between 67 and $72 \mu \mathrm{m}$, corresponding to the dimensions obtained from the Ni-shim master structure; "smaller mushroom" with diameters ranging between 56 and $67 \mu \mathrm{m}$; and "no mushroom" with diameters smaller than $56 \mu \mathrm{m}$ associated with the absence of mushroom tips. Clearly, all three conditions tested in the first tests led to "small mushrooms" with diameters ranging from

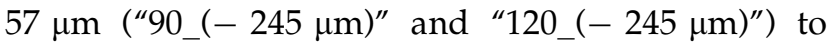
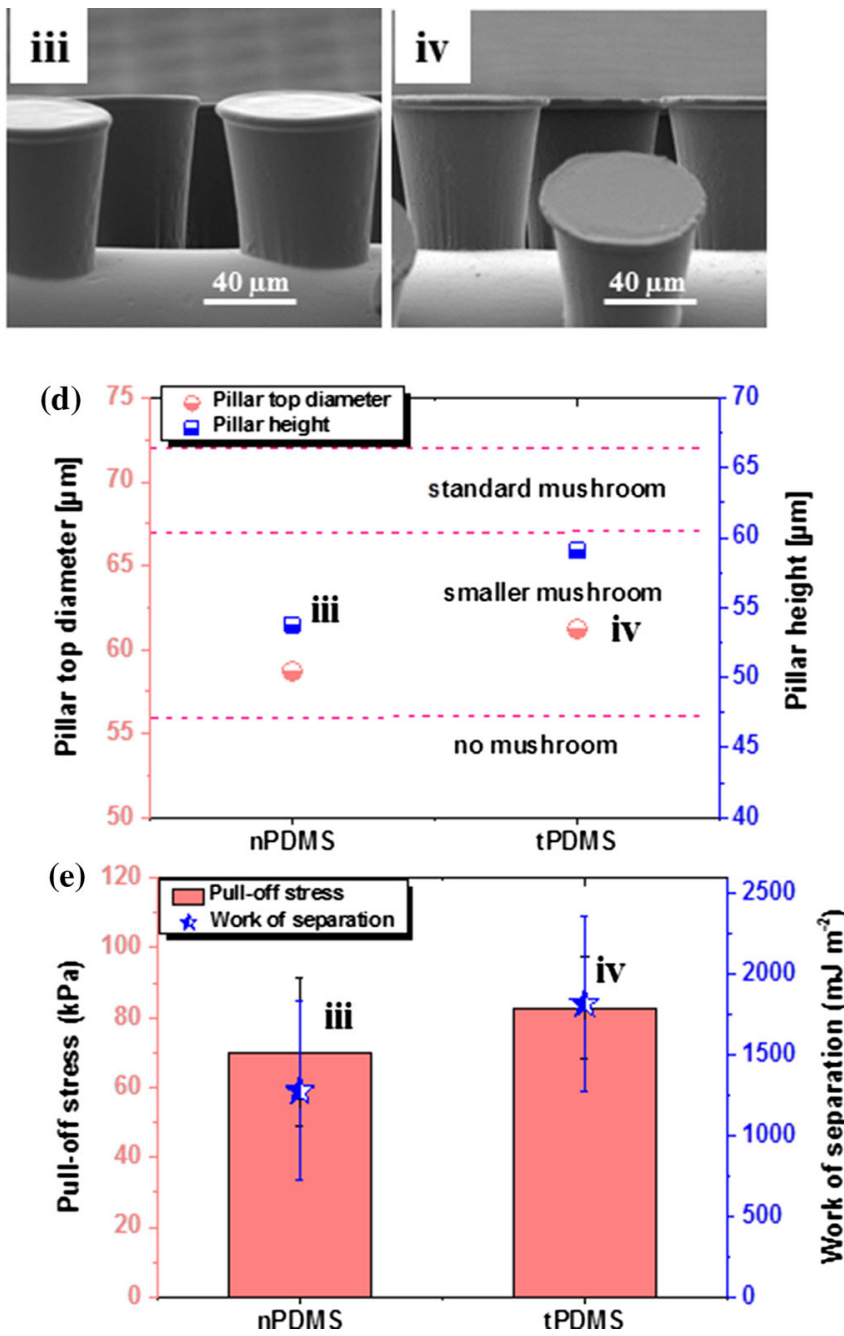

on $\mathbf{b}$ morphology, i.e., pillar top diameter and pillar height and on c pull-off stress and work of separation (all samples with $90-\mu \mathrm{m}-$ thick top layer obtained at $d=-245 \mu \mathrm{m}$ ). Effect of different types of PDMS template (nPDMS and tPDMS) on $\mathbf{d}$ morphology, i.e., pillar top diameter and pillar height and on e adhesion, i.e., pull-off stress and work of separation (all samples with $120-\mu \mathrm{m}$ thick top layer obtained at $d=-303 \mu \mathrm{m}$ ).

$60 \mu \mathrm{m}$ ("120_(-303 $\mu \mathrm{m})$ "). Thus, the diameter slightly increased with more negative distances, i.e., higher compressive loads between the imprinting and the pressure roll. The pillar heights ranged between 53 and $56 \mu \mathrm{m}$. The specimens made from $120-\mu \mathrm{m}$-thick wet coatings and the highest compressive loads $(d=-303 \mu \mathrm{m})$ showed the best adhesion performance with a pull-off stress about $70 \mathrm{kPa}$ and a work of separation about $1.25 \mathrm{~J} \mathrm{~m}^{-2}$ (Fig. 3c), which most probably is related to the largest mushroom caps obtained under these conditions [47]. 
(a)

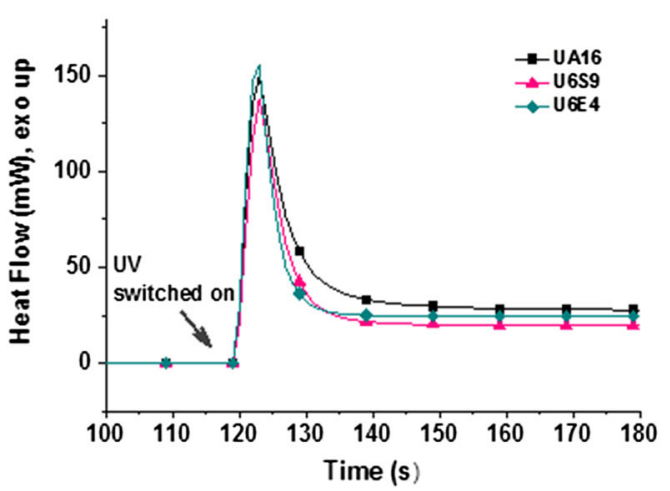

(c)

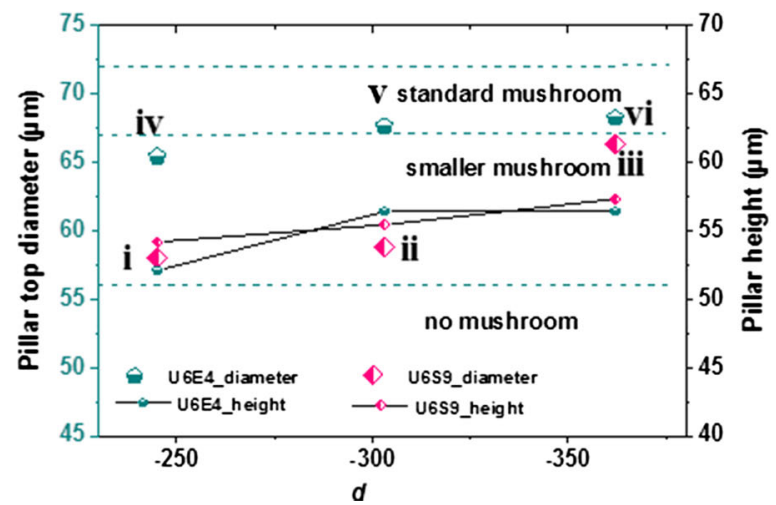

Figure 5 Influence of material composition (mixture of different polyurethane acrylates) on patterned microstructure and adhesion properties: a curing rate of oligomers determined by photo-DSC. b Scanning electron micrographs of micropillars: (i)-(iii) made of U6S9, fabricated at $d=-245 \mu \mathrm{m},-303 \mu \mathrm{m}$ and $-363 \mu \mathrm{m}$,

In addition to compression during the imprint, UVcuring conditions are crucial for the cross-linking density and curing kinetics. We evaluated the impact of the UV power and the transparency of the silicone template (Fig. 4). Results for two different power ratings of the UV lamp are shown in (i) and (ii) in Figs. 4a-d. The micrographs reveal that microstructures exposed to $30 \% \mathrm{UV}$ power exhibited no mushrooms (Fig. 4a). For 50\% UV power, mushroom caps were obtained, but their size was still very small. Adhesion tests shown in Fig. 4c confirmed the results; by increasing the UV power to $50 \%$, the pulloff stress was improved by $17 \%$ and the work of separation by $29 \%$.

To further explore the effect related to UV exposure, the non-transparent silicone template (nPDMS) used in previous tests was replaced by a translucent (b)
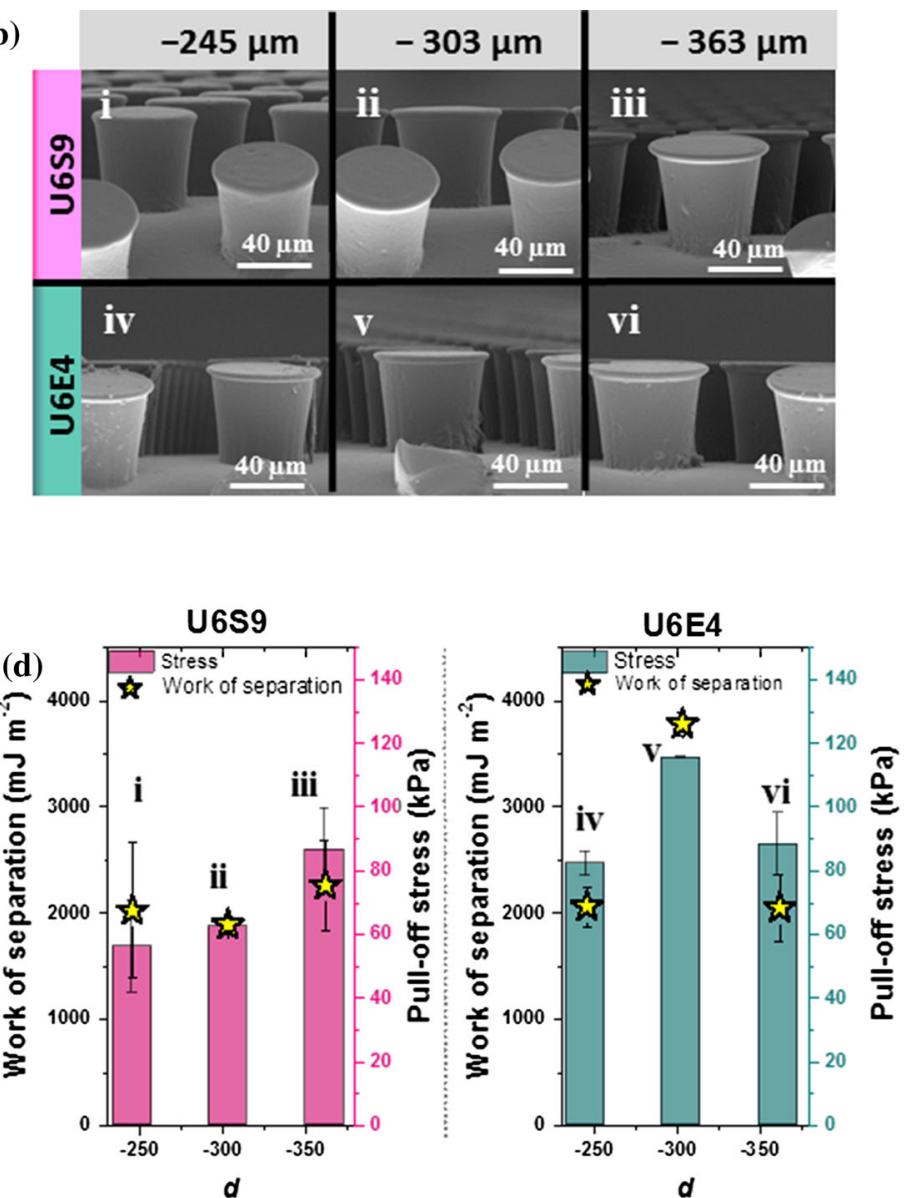

respectively; (iv)-(vi) made of U6E4, fabricated at $d=-245 \mu \mathrm{m},-303 \mu \mathrm{m} \quad$ and $-363 \mu \mathrm{m}$, respectively. Adhesive composition effect on $\mathrm{c}$ morphology, i.e., pillar top diameter and pillar height and on $\mathbf{d}$ pull-off stress and work of separation. The samples were made of U6S9 and U6E4.

silicone template (tPDMS). This modification led to much larger mushroom caps with tip diameters of up to $61 \mu \mathrm{m}$, as presented in (iii) and (iv) in Figs. 4a and d. In addition to larger caps, the structures were elongated with pillar heights of $59 \mu \mathrm{m}$, compared to $54 \mu \mathrm{m}$ for structures generated by the non-transparent template. Figure 4e summarizes the adhesion performance of the micropatterned adhesives obtained using the different templates: Micropatterned adhesives replicated by using the translucent templates exhibited significantly higher pull-off stress $(83 \mathrm{kPa})$ and work of separation $\left(1.8 \mathrm{~J} \mathrm{~m}^{-2}\right)$ compared to the adhesives generated by non-transparent templates with a pull-off stress of $70 \mathrm{kPa}$ and a work of separation of $1.3 \mathrm{~J} \mathrm{~m}^{-2}$. The larger mushroom caps accompanied with the enhanced adhesion performance are likely related to better penetration of 


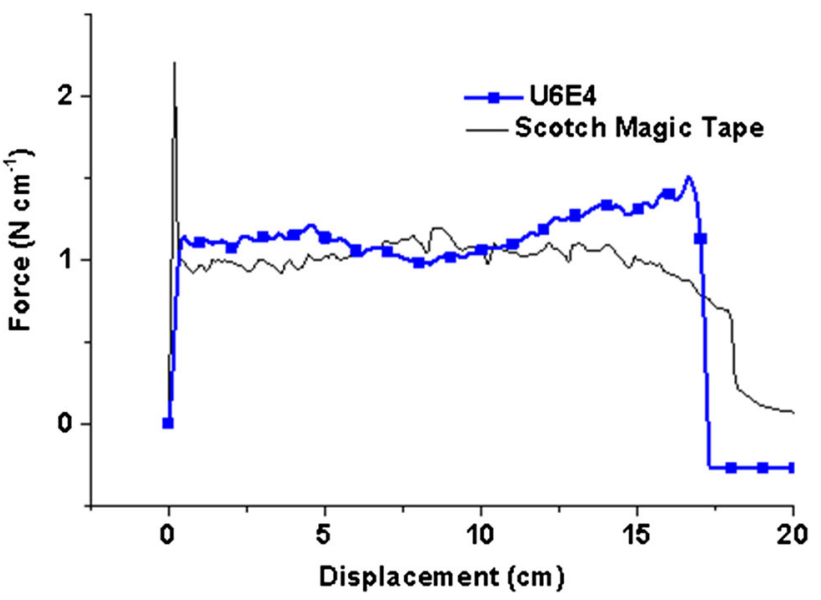

Figure $690^{\circ}$ peel test results of adhesive film U6E4 (obtained at $d=-303 \mu \mathrm{m})$. Scotch magic tape was used as reference.

UV light through the translucent template. Thus, the complete mushroom-shaped microstructure including the undercut of the mushroom cap was homogeneously cured. In addition, the transparent mold was less flexible (approx. two times stiffer, see Table 1) compared to the non-transparent template. Thus, the tPDMS template is less compressed during the imprint, which most probably explains the longer pillars. As a disadvantage, we observed that, after

Figure 7 Normal and shear adhesion demonstration:

a demonstration of shear adhesion and reusability of the adhesive film of U6E4 (obtained at $d=-303 \mu \mathrm{m}$ ). Time-lapse photographs show handling of a glass prism with mass $1.163 \mathrm{~kg}$. The "attaching-movingdetaching-reattaching” procedure was repeated for 5 times. The contact area was controlled around $20 \mathrm{~mm} \times 10 \mathrm{~mm}$. b Normal adhesion demonstration of the dry adhesive film of U6E4 (obtained at $d=-303 \mu \mathrm{m}$ ) by lifting a glass weight of $1163 \mathrm{~g}$. The contact area was $20 \mathrm{~mm} \times 40 \mathrm{~mm}$. (a)

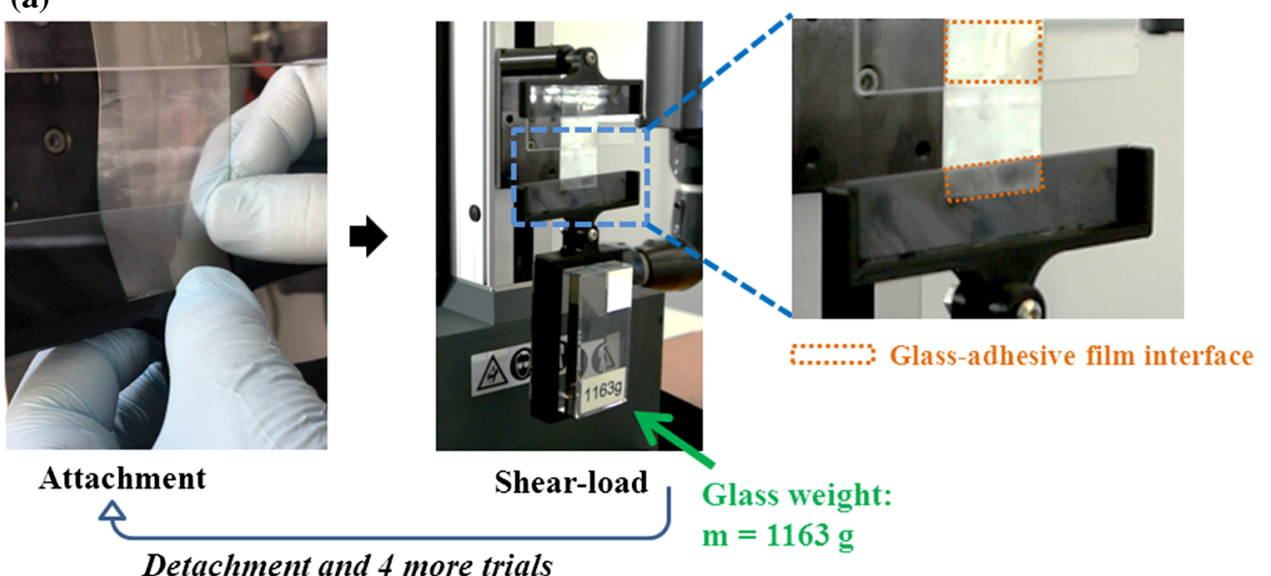

(b)

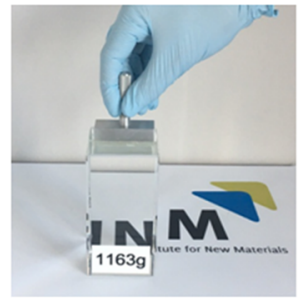

Attachment several imprint cycles, microstructures ruptured during demolding from the translucent template (tPDMS) and stuck inside the cavities. An explanation for this is that UA16 resin diffused into the tPDMS template upon repeated imprints. This can result in strong covalent bonds between the prepolymer inside the cavity and the interpenetrated reactive oligomers, which in turn led to cohesive rupture of the microstructures. In contrast, repeated imprinting using the nPDMS was always successful without any residues inside the cavities upon demolding.

\section{Material optimization}

Besides process parameters, different material compositions (UA16-based polymer blends) were evaluated to further improve the formation of mushroom caps by enhancing the UV-curing kinetics. The parameters of the replication process for the different blends are summarized in Table 2. The kinetics of the UV-induced curing was modified by adding to UA16 either 1\% Miramer SIP900 (polymer blend: U6S9) or 20\% Miramer ES4420 (polymer blend: U6E4). Figure $5 \mathrm{a}$ shows the results of the photo-differential scanning calorimetry (UV-DSC), which implies that 


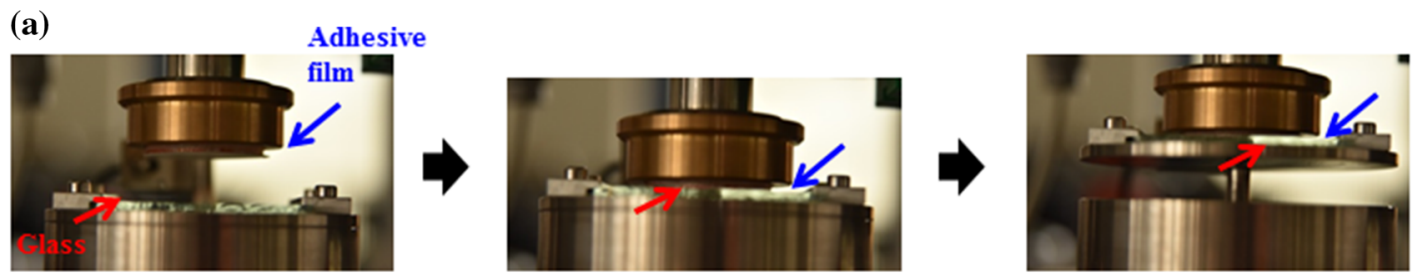

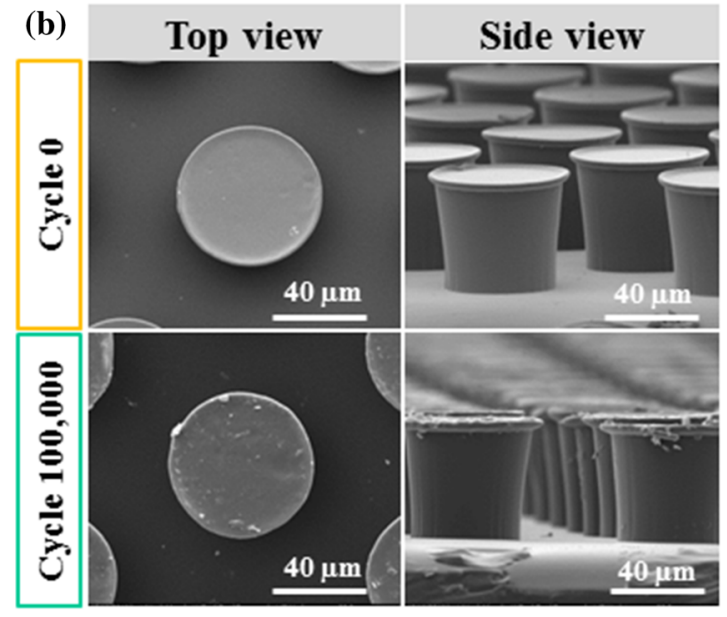

Figure 8 Endurance test of the adhesive film of U6E4 (obtained at $d=-303 \mu \mathrm{m})$ : a Photographs show that the customized automated device equipped with the adhesive film adheres to a glass substrate. The "attachment and releasing by shearing"

U6E4 cross-linked more quickly compared to U6S9 and UA16. In addition, mercapto-modified acrylate oligomers (U6E4) are well known to reduce the oxygen inhibition during a radical polymerization reaction [48]. In contrast to the tests presented above, the composition of the ground (first) layer was modified by adding 10\% Laromer 8887 (polymer blend: U6L7), i.e., a mono-functional acrylic acid ester. Laromer 8887 acted as "thinner" [30, 33] by reducing the cross-linking density accompanied with polymer stiffness reduction and lower elongation at break (see values in Table 1). Micrographs of microstructures obtained from U6S9 (i-iii) and U6E4 (iv-vi) in terms of varying pressing distances are shown in Fig. 5b. Dimensions of the microstructures are reported in Fig. 5c. For U6S9, the diameter of the pillar diameter increased from 58 to $66 \mu \mathrm{m}$ with decreasing pressing distance from -245 to -363 $\mu \mathrm{m}$. For U6E4, the mushroom caps were larger and less sensitive to the pressing distances. Thus, diameters of the mushroom tips varied between 65 and $67 \mu \mathrm{m}$. The adhesion experiments confirmed these trends: The pull-off stresses obtained for U6S9 increased from 56 to $87 \mathrm{kPa}$ with decreasing pressing (c)

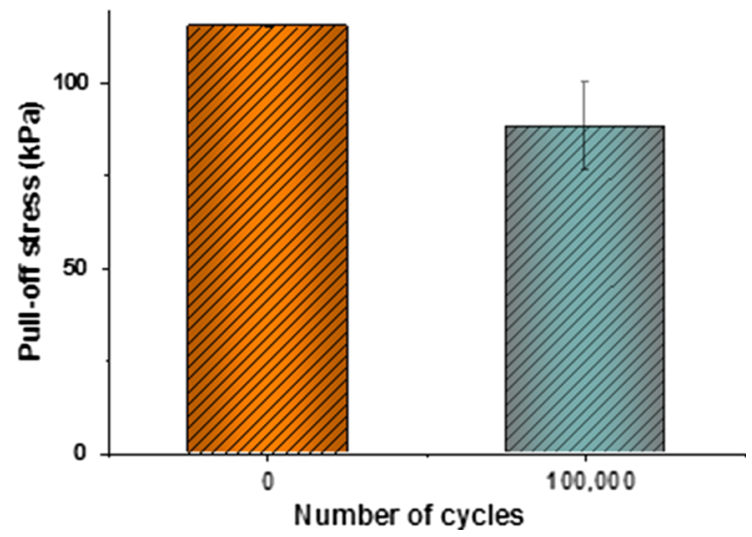

procedure is defined as one cycle. Results of the adhesive film after 100,000 cycles (Cycle 100,000) are compared to that before endurance test started (Cycle 0) in terms of: $\mathbf{b}$ scanning electron images c pull-off stress.

distance from -245 to $-363 \mu \mathrm{m}$. The work of separation was about $2 \pm 0.2 \mathrm{~J} \mathrm{~m}^{-2}$ for all U6S9 specimens. The best adhesion performance was obtained for U6E4 with the highest pull-off stress of $116 \mathrm{kPa}$ and the highest work of separation of $3.78 \mathrm{~J} \mathrm{~m}^{-2}$ for specimens made with a pressing distance of $-303 \mu \mathrm{m}$.

\section{Application demonstrations}

Following process and material optimization, micropatterned adhesive films of U6E4 were continuously fabricated at a pressing distance of $-303 \mu \mathrm{m}$. The adhesion properties and durability of the adhesive films obtained were further characterized. Figure 6 shows the peel adhesion of the micropatterned U6E4 film in comparison with $3 \mathrm{M}$ Scotch Magic tape. For both films, we found similar peel forces between 1 and $1.4 \mathrm{~N} \mathrm{~cm}^{-1}$ for a $90^{\circ}$ peel angle. Inspection upon tests revealed residue-free detachment for both films. Using lap shear test, a shear strength of the micropatterned U6E4 film of about $71 \pm 9 \mathrm{kPa}$ was obtained. In Fig. 7a, the reusability and shear adhesion of a 20-mm-wide U6E4 film were demonstrated 
by handling a glass object $(1.163 \mathrm{~kg})$ : Upon attachment of the film, the object was lifted (shear-loaded), placed at the target position and the adhesive film was peeled off and attached again. The procedure was successfully repeated 5 times without any damage of the structure nor residues at the glass surface. Figure $7 \mathrm{~b}$ demonstrates a similar test for the normal loading direction. Here, upon attachment, the glass object was normally lifted and placed at the target position. The cycle including attachment, lifting and detachment was successfully repeated 5 times without any visible damages nor residues.

The durability of the micropatterned dry adhesive was examined by a long-term pick-and-place test. A circular pad of adhesive film (U6E4, produced with $d=-303 \mu \mathrm{m}$; diameter $30 \mathrm{~mm}$ ) repeatedly picked up and released a glass plate with mass of $145 \mathrm{~g}$ for 100,000 attachment-detachment cycles (see Fig. 8a). After these cycles, the micropatterned structure exhibited a certain extent of abrasion and contamination (see Fig. 8b). Similarly, the pull-off stress decreased from nearly $120 \mathrm{kPa}$ to around $90 \mathrm{kPa}$ (see Fig. 8c). However, the pick-and-place action can be still well performed even after 100,000 cycles, demonstrating a good endurance of PUA dry adhesive.

\section{Conclusions}

The present paper has shown that achieving optimum mushroom tips can be a challenge for fabrication by roll-to-roll processing. The results presented demonstrate that the formation of mushroom caps during imprinting is strongly connected with the UVcuring conditions and the materials used. The following conclusions can be drawn:

- Process parameters for optimum mushroom tips: The absence of mushroom tips is related to insufficient UV curing, but the quality of the replicated microstructures can be improved by increasing UV power, the choice of translucent templates or adding of chemical components accelerating the curing kinetics. For example, cap size was much larger by using the translucent template, but microstructures stuck inside the cavities after several imprint cycles, being inacceptable for continuous fabrication.
- Effect of UV treatment on adhesion performance: Only mushroom tips that were completely replicated in their size show high adhesion performance. By increasing UV power from 30 to $50 \%$, the pull-stress was improved by $17 \%$ and work of separation by $29 \%$. Replacing opaque template with translucent template resulted in a pull-off stress increase by $19 \%$.

- Effect of material modification on adhesion performance: Adding polyester-modified silicone acrylates (Miramer SIP900) or mercapto-modified acrylates (Miramer ES4420) accelerated the crosslinking kinetics. In particular, the polymer blend U6E4 provided best results in mushroom cap sizes similar to the master structure and excellent adhesion performance: pull-off stress of $116 \mathrm{kPa}$ work of separation of $3.78 \mathrm{~J} \mathrm{~m}^{-2}$, significantly larger compared to structures made from pure, unmodified UA16.

- Comparison of adhesion performance: A peel strength of $1.4 \mathrm{~N} \mathrm{~cm}^{-1}$ similar to commercial Scotch Magic tape and a shear strength of $71 \mathrm{kPa}$ were achieved with the optimized micropatterned adhesive. Repeated attachmentdetachment cycles without loss of the functionality proved reliable usability and robustness of the micropatterned dry adhesive for versatile application.

\section{Acknowledgements}

This work was funded by the European Research Council (ERC) under the European Union's Seventh Framework Programme (FP/2007-2013)/ERC Advanced Grant Agreement no. 340929 and by the Leibniz-Competition Grant no. 493. We thank Jennifer Dollmann for the dynamic mechanical thermal analysis, Marcus Koch for the help on SEM measurements, Florent Zogaj and Sebastian Meyer for their assistance on adhesion measurements.

\section{Compliance with ethical standards}

Conflict of interest The authors declare that they have no conflict of interest.

Open Access This article is distributed under the terms of the Creative Commons Attribution 4.0 International License (http://creativecommons.org/ 
licenses/by/4.0/), which permits unrestricted use, distribution, and reproduction in any medium, provided you give appropriate credit to the original author(s) and the source, provide a link to the Creative Commons license, and indicate if changes were made.

\section{References}

[1] Gorb S, Gorb E, Kastner V (2001) Scale effects on the attachment pads and friction forces in syrphid flies (diptera, syrphidae). J Exp Biol 204:1421-1431

[2] Labonte D, Clemente CJ, Dittrich A, Kuo C-Y, Crosby AJ, Irschick DJ, Federle W (2016) Extreme positive allometry of animal adhesive pads and the size limits of adhesion-based climbing. Proc Natl Acad Sci USA 113:1297-1302. https://d oi.org/10.1073/pnas.1519459113

[3] Arzt E, Gorb S, Spolenak R (2003) From micro to nano contacts in biological attachment devices. Proc Natl Acad Sci USA 100(19):10603-10606. https://doi.org/10.1073/pna s. 1534701100

[4] Autumn K, Liang YA, Hsieh ST, Zesch W, Chan WP, Kenny TW, Fearing R (2000) Full RJ (2000) Adhesive force of a single gecko foot-hair. Nature (Lond) 405:681-685

[5] Federle W (2006) Why are so many adhesive pads hairy? J Exp Biol 209(14):2611-2621. https://doi.org/10.1242/jeb. 02323

[6] Kamperman M, Kroner E, del Campo A, McMeeking RM, Arzt E (2010) Functional adhesive surfaces with "Gecko" effect: the concept of contact splitting. Adv Eng Mater 12(5):335-348. https://doi.org/10.1002/adem.201000104

[7] Hensel R, Moh K, Arzt E (2018) Engineering micropatterned dry adhesives: from contact theory to handling applications. Adv Funct Mater 28:1800865. https://doi.org/10.1002/adfm. 201800865

[8] del Campo A, Greiner C, Álvarez I, Arzt E (2007) Patterned surfaces with pillars with controlled 3D Tip geometry mimicking bioattachment devices. Adv Mater 19(15):1973-1977. https://doi.org/10.1002/adma.200602476

[9] Cheung E, Sitti M (2009) Adhesion of biologically inspired polymer microfibers on soft surfaces. Langmuir 25(12):6613-6616. https://doi.org/10.1021/la900997p

[10] Spolenak R, Gorb S, Arzt E (2005) Adhesion design maps for bio-inspired attachment systems. Acta Biomater 1(1):5-13. https://doi.org/10.1016/j.actbio.2004.08.004

[11] del Campo A, Greiner C, Arzt E (2007) Contact shape controls adhesion of bioinspired fibrillar surfaces. Langmuir 23(20):10235-10243. https://doi.org/10.1021/la7010502
[12] Boesel LF, Greiner C, Arzt E, del Campo A (2010) Geckoinspired surfaces: a path to strong and reversible dry adhesives. Adv Mater 22(19):2125-2137. https://doi.org/10.100 2/adma.200903200

[13] T-i Kim, Jeong HE, Suh KY, Lee HH (2009) Stooped nanohairs: geometry-controllable, unidirectional, reversible, and robust gecko-like dry adhesive. Adv Mater 21(22):2276-2281. https://doi.org/10.1002/adma.200803710

[14] Greiner C, Spolenak R, Arzt E (2009) Adhesion design maps for fibrillar adhesives: the effect of shape. Acta Biomater 5(2):597-606. https://doi.org/10.1016/j.actbio.2008.09.006

[15] Hui CY, Glassmaker NJ, Tang T, Jagota A (2004) Design of biomimetic fibrillar interfaces: 2. Mechanics of enhanced adhesion. J R Soc Interface 1(1):35-48. https://doi.org/10. 1098/rsif.2004.0005

[16] Khaderi SN, Fleck NA, Arzt E, McMeeking RM (2015) Detachment of an adhered micropillar from a dissimilar substrate. J Mech Phys Solids 75:159-183. https://doi.org/ 10.1016/j.jmps.2014.11.004

[17] Khaled WB, Sameoto D (2013) Anisotropic dry adhesive via cap defects. Bioinspir Biomim 8(4):044002. https://doi.org/ 10.1088/1748-3182/8/4/044002

[18] Heepe L, Gorb SN (2014) Biologically inspired mushroomshaped adhesive microstructures. Annu Rev Mater Res 44(1):173-203. https://doi.org/10.1146/annurev-matsci-062 910-100458

[19] Fischer SCL, Arzt E, Hensel R (2016) Composite pillars with a tunable interface for adhesion to rough substrates. ACS Appl Mater Interfaces 9(1):1036-1044. https://doi.org/ 10.1021/acsami.6b11642

[20] Balijepalli RG, Fischer SCL, Hensel R, McMeeking RM, Arzt E (2017) Numerical study of adhesion enhancement by composite fibrils with soft tip layers. J Mech Phys Solids 99:357-378. https://doi.org/10.1016/j.jmps.2016.11.017

[21] Maugis D, Barquins M (1978) Fracture mechanics and the adherence of viscoelastic bodies. J Phys D Appl Phys 11:1989-2023

[22] Labonte D, Federle W (2015) Rate-dependence of "wet" biolgocial adhesives and the function of the pad secretion in insects. Soft Matter 11:8661-8673. https://doi.org/10.1039/ C5SM01496D

[23] Creton C (1999) Micromechanics of flat-probe adhesion tests of soft viscoelastic polymer films. J Polym Sci Part B Polym Phys 38:965-979

[24] Barreau V, Hensel R, Guimard NK, Ghatak A, McMeeking RM, Arzt E (2016) Fibrillar elastomeric micropatterns create tunable adhesion even to rough surfaces. Adv Funct Mater 26(26):4687-4694. https://doi.org/10.1002/adfm.201600652

[25] Barreau V, Yu D, Hensel R, Arzt E (2017) Elevated temperature adhesion of bioinspired polymeric micropatterns to 
glass. J Mech Behav Biomed Mater 76:110-118. https://doi. org/10.1016/j.jmbbm.2017.04.007

[26] Cadirov N, Booth JA, Turner KL, Israelachvili JN (2017) Influence of humidity on grip and release adhesion mechanisms for gecko-inspired microfibrillar surfaces. ACS Appl Mater Interfaces 9(16):14497-14505. https://doi.org/10.102 1/acsami.7b01624

[27] Purtov J, Verch A, Rogin P, Hensel R (2018) Improved development procedure to enhance the stability of microstructures created by two-photon polymerization. Microelectron Eng 194:45-50. https://doi.org/10.1016/j.mee. 2018.03.009

[28] Fischer SCL, Groß K, Torrents Abad O, Becker MM, Park E, Hensel R, Arzt E (2017) Funnel-shaped microstructures for strong reversible adhesion. Adv Mater Interfaces 4(20):1700292. https://doi.org/10.1002/admi.201700292

[29] Yi H, Kang M, Kwak MK, Jeong HE (2016) Simple and reliable fabrication of bioinspired mushroom-shaped micropillars with precisely controlled tip geometries. ACS Appl Mater Interfaces 8(34):22671-22678. https://doi.org/ 10.1021/acsami.6b07337

[30] Choi S-J, Kim HN, Bae WG, Suh K-Y (2011) Modulus- and surface energy-tunable ultraviolet-curable polyurethane acrylate: properties and applications. J Mater Chem 21(38):14325-14335. https://doi.org/10.1039/c1jm12201k

[31] Choi S-J, Yoo PJ, Baek SJ, Kim TW, Lee HH (2004) An ultraviolet-curable mold for sub-100-nm lithography. J Am Chem Soc 126:7744-7745

[32] Yoo PJ, Choi S-J, Kim JH, Suh D, Baek SJ, Kim TW, Lee HH (2004) Unconventional patterning with a modulus-tunable mold: from imprinting to microcontact printing. Chem Mater 16:5000-5005

[33] Leitgeb M, Nees D, Ruttloff S, Palfinger U, Götz J, Liska R, Belegratis MR, Stadlober B (2016) Multilength scale patterning of functional layers by roll-to-roll ultraviolet-lightassisted nanoimprint lithography. ACS Nano 10(5):4926-4941. https://doi.org/10.1021/acsnano.5b07411

[34] Yi H, Hwang I, Lee JH, Lee D, Lim H, Tahk D, Sung M, Bae W-G, Choi S-J, Kwak MK, Jeong HE (2014) Continuous and scalable fabrication of bioinspired dry adhesives via a roll-to-roll process with modulated ultraviolet-curable resin. ACS Appl Mater Interfaces 6(16):14590-14599. https://doi. org/10.1021/am503901f

[35] Jeong HE, Lee JK, Kim HN, Moon SH, Suh KY (2009) A nontransferring dry adhesive with hierarchical polymer nanohairs. Proc Natl Acad Sci USA 106(14):5639-5644. h ttps://doi.org/10.1073/pnas.0900323106

[36] Jeong HE, Kwak R, Khademhosseini A, Suh KY (2009) UVassisted capillary force lithography for engineering biomimetic multiscale hierarchical structures: from lotus leaf to gecko foot hairs. Nanoscale 1:331-338. https://doi.org/10. 1039/b9nr00106a

[37] Jeong HE, Suh KY (2012) Precise tip shape tranformation of nanopillars for enhanced dry adhesion strength. Soft Matter 8:5375-5380. https://doi.org/10.1039/c2sm07440k

[38] Jeong HE, Lee SH, Kim P, Suh KY (2006) Stretched polymer nanohairs by nanodrawing. Nano Lett 6:1508-1513

[39] Suh D, Tak H, S-j Choi, T-i Kim (2015) Permeability- and surface-energy-tunable polyurethane acrylate molds for capillary force lithography. ACS Appl Mater Interfaces 7(43):23824-23830. https://doi.org/10.1021/acsami.5b 06975

[40] Decker C (2002) Kinetic study and new applications of UV radiation curing. Macromol Rapid Commun 23:1067-1093

[41] Hensel R, Finn A, Helbig R, Braun H-G, Neinhuis C, Fischer W-J, Werner C (2014) Biologically inspired omniphobic surfaces by reverse imprint lithography. Adv Mater 26:2029-2033. https://doi.org/10.1002/adma.201305408

[42] Finn A, Hensel R, Hagemann F, Kirchner R, Jahn A, Fisher W-J (2012) Geometrical properties of multilayer nano-imprint-lithography molds for optical applications. Microelectron Eng 98:284-287. https://doi.org/10.1016/j.mee.2012.04. 022

[43] Lee SH, Yi H, Park CW, Jeong HE, Kwak MK (2018) Continuous tip widening technique for roll-to-roll fabrication of dry adhesives. Coatings 8:349-355. https://doi.org/10.33 90/coatings8100349

[44] Yu D, Beckelmann D, Opsölder M, Schäfer B, Moh K, Hensel R, Oliveira PWd, Arzt E (2019) Roll-to-roll manufacturing of micropatterned adhesives by template compression. Materials 12:97

[45] Wu S (1973) Polar and nonpolar interactions in adhesion. J Adhes 5(1):39-55. https://doi.org/10.1080/ 00218467308078437

[46] Wu S (1971) Calculation of interfacial tension in polymer systems. J Polym Sci C 34:19-30

[47] Balijepalli RG, Begley MR, Fleck NA, McMeeking RM, Arzt E (2016) Numerical simulation of the edge stress singularity and the adhesion strength for compliant mushroom fibrils adhered to rigid substrates. Int $\mathrm{J}$ Solids Struct 85-86:160-171. https://doi.org/10.1016/j.ijsolstr.2016.02. 018

[48] Husár B, Ligon SC, Wutzel H, Hoffmann H, Liska R (2014) The formulator's guide to anti-oxygen inhibition additives. Prog Org Coat 77(11):1789-1798. https://doi.org/10.1016/j. porgcoat.2014.06.005

Publisher's Note Springer Nature remains neutral with regard to jurisdictional claims in published maps and institutional affiliations. 